\title{
PERONEAL SPASTIC FLAT FOOT
}

\author{
N. J. Blockey, Manchester, ENgland \\ From the University Department of Orthopaedic Surgery, Manchester Royal Infirmary
}

The acquired deformity of peroneal spastic flat foot has posed many problems since its description by Sir Robert Jones $(1897,1916)$. Although radiographic anomalies in the tarsus have been emphasised in recent years (Harris and Beath 1948), there is no general agreement on their significance. Opinions on the etiology, mechanism and treatment have shown a wide divergence. On this account I have investigated thirty cases of peroneal spastic flat foot and observed the effects of a standard method of treatment over the course of two years. Among the problems that I have studied are the correlation between physical signs and radiographic findings, and the nature of the muscle pull that produces the deformity.

\section{CLINICAL MATERIAL AND METHODS OF INVESTIGATION}

Thirty feet in twenty-seven patients were investigated. Cases of generalised tarsal arthritis, which can give a closely similar picture, were excluded. Although I have not been able to elicit passive inversion when the patient was fully relaxed-a finding considered essential to the diagnosis by Sir Robert Jones-the cases have satisfied all the other diagnostic criteria: eversion deformity and pain of recent onset with free ankle movement, but with resistance to inversion by tight tendons on the outer side of the tarsus. Patients with a long history of flat foot with increasing pain and generalised stiffness of the tarsus have been excluded. Patients with bilateral deformity but unilateral symptoms are included as one case. In the clinical investigation I have taken into account the height and weight, build, psychological make-up, age, length of history and mode of onset, the posture of the foot and state of the arch before treatment, the degree of wasting of the leg, and the presence or absence of other neurological changes. The erythrocyte sedimentation rate and the differential sheep-cell agglutination test have been performed to try to pick up cases of early rheumatoid arthritis. Note has been made of the tendons that appeared, clinically, to be responsible for the deformity. Antero-posterior and lateral radiographs, oblique tarsal views (Seddon 1932) and the posterior axial view favoured by Harris and Beath (1948) have been obtained. Finally, fifty feet from normal individuals aged between thirteen and seventeen have been examined clinically and radiographically to assess the frequency of anomalies of this type in the population.

Additional investigations were undertaken in some cases in which the foot relapsed after treatment, and in some showing particularly striking clinical features. Electromyography was carried out in two cases, using surface and needle electrodes. The lateral compartment of the leg was explored under local anaesthesia in three patients to determine visually which muscle-tendon unit was responsible for the deformity. When the peroneus brevis seemed to be largely responsible its nerve supply was crushed, leaving the nerves to the other evertors intact. The so-called reflex spasm was studied by injecting the sinus tarsi with anaesthetic solutions, and in the course of fusion operations material was taken for histological examination.

In all cases the foot was examined under anaesthesia to assess the degree and rigidity of the eversion. A walking plaster was then applied with the foot inverted as far as possible and retained for three months, after which the range of active and passive movement was determined. Thereafter treatment has been by physiotherapy, sometimes with lateral steels and shoe alterations for the rest of two years. When subtalar and midtarsal arthrodesis was required it was undertaken at the end of the two-year period. 


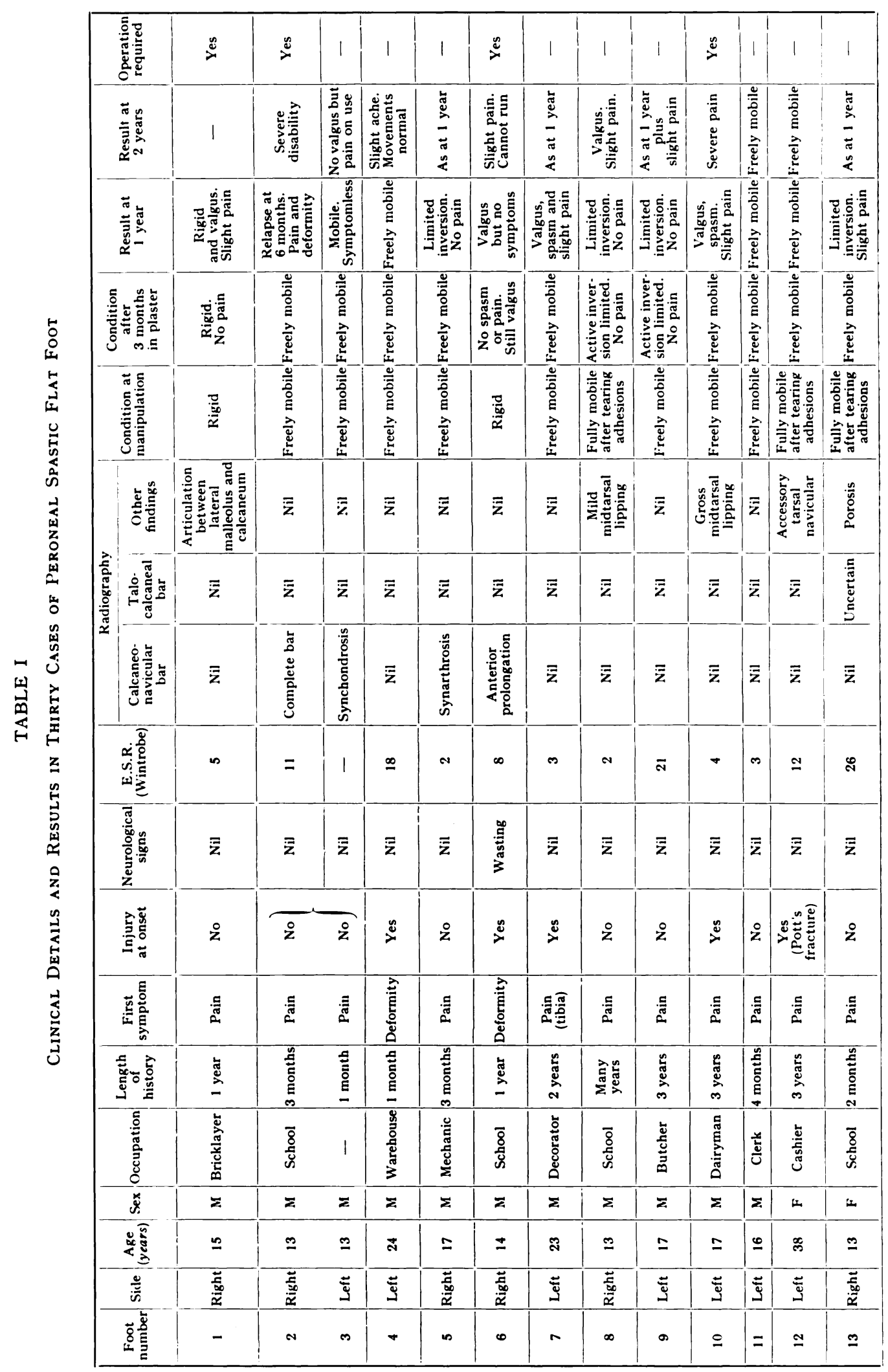




\begin{tabular}{|c|c|c|c|c|c|c|c|c|c|c|c|c|c|c|c|c|}
\hline 1 & 1 & 1 & 1 & | & 1 & i & 1 & 1 & 1 & 1 & 1 & 1 & 1 & I & 1 & I \\
\hline 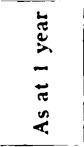 & 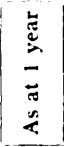 & 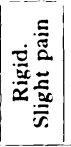 & 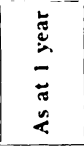 & 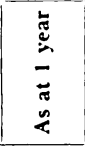 & 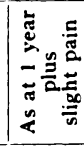 & 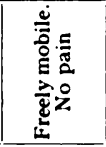 & 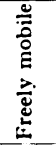 & 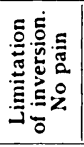 & 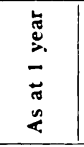 & 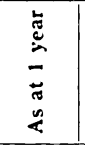 & 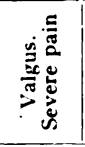 & 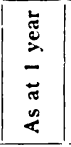 & 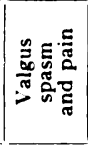 & 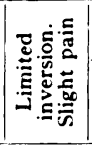 & 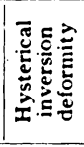 & 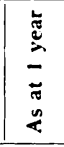 \\
\hline 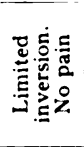 & 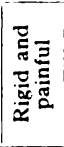 & 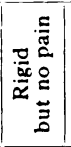 & 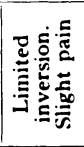 & 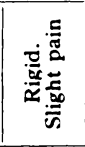 & 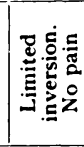 & 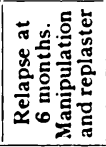 & 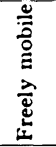 & 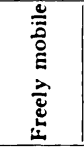 & 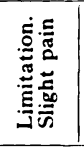 & $\mid$ & 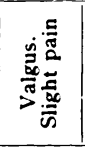 & 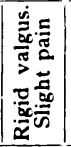 & 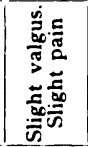 & 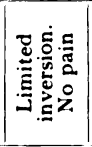 & 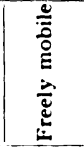 & 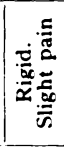 \\
\hline 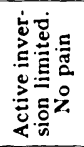 & $\begin{array}{l}\bar{z} \\
\bar{x}\end{array}$ & $\frac{\bar{x}}{\tilde{\alpha}}$ & 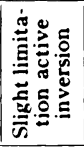 & 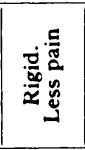 & 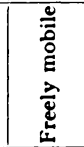 & 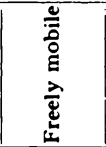 & 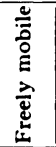 & 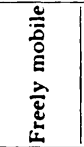 & 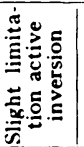 & 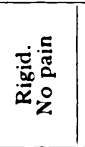 & 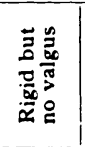 & 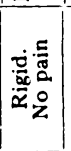 & 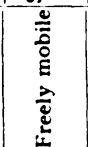 & 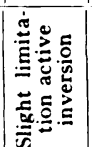 & 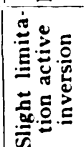 & 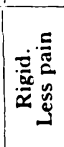 \\
\hline 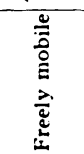 & $\mid \begin{array}{l}\vec{v} \\
\overline{\tilde{g}}\end{array}$ & $\mid \begin{array}{l}\widetilde{c} \\
\tilde{\alpha}\end{array}$ & 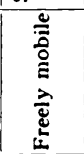 & 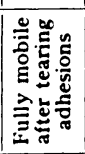 & 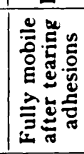 & 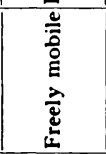 & 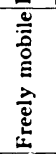 & 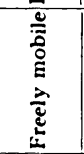 & 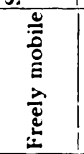 & $\begin{array}{l}\widetilde{\widetilde{w}} \\
\overline{\alpha u}\end{array}$ & 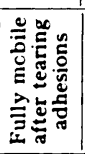 & 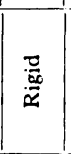 & 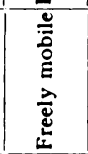 & 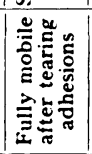 & 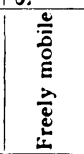 & $\frac{\bar{c}}{\widetilde{\underline{w}}}$ \\
\hline 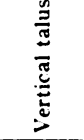 & $\overline{\bar{z}}$ & 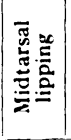 & 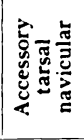 & 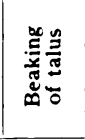 & $\bar{\Sigma}$ & $\overline{\bar{\alpha}}$ & $\overline{\bar{z}}$ & $\bar{z}$ & 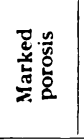 & 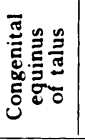 & $\overline{\bar{z}}$ & 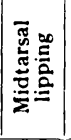 & $\overline{\bar{z}}$ & $\overline{\bar{z}}$ & $\overline{\bar{z}}$ & 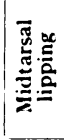 \\
\hline $\bar{z}$ & $\overline{\bar{z}}$ & 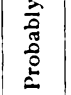 & $\bar{z}$ & $\overline{\bar{z}}$ & $\overline{\bar{z}}$ & $\bar{z}$ & $\bar{z}$ & $\bar{z}$ & $\overline{\mathbf{z}}$ & $\stackrel{\check{\nu}}{\check{\nu}}$ & $\overline{\bar{z}}$ & $\underset{\nu}{\check{\nu}}$ & $\bar{z}$ & $\overline{\bar{z}}$ & $\overline{\bar{z}}$ & $\check{\check{\beth}}$ \\
\hline $\bar{z}$ & 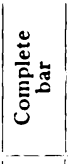 & $\overline{\bar{z}}$ & $\overline{\bar{z}}$ & 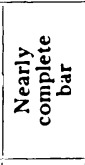 & $\overline{\bar{z}}$ & 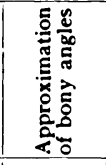 & $\overline{\bar{z}}$ & $\overline{\bar{z}}$ & $\bar{z}$ & $\overline{\bar{z}}$ & 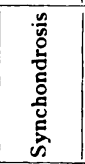 & $\bar{z}$ & 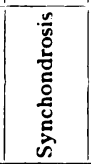 & 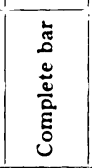 & $\overline{\bar{z}}$ & $\overline{\bar{z}}$ \\
\hline$N$ & + & 0 & $\infty$ & + & 0 & 0 & 0 & + & N & N & $\infty$ & N & $\infty$ & $\infty$ & 0 & $\Xi$ \\
\hline $\bar{z}$ & $\overline{\bar{z}}$ & $\overline{\bar{z}}$ & $\overline{\bar{z}}$ & $\overline{\bar{z}}$ & $\overline{\bar{z}}$ & $\overline{\bar{z}}$ & $\overline{\bar{z}}$ & $\bar{z}$ & $\bar{\Sigma}$ & $\overline{\bar{z}}$ & $\overline{\bar{z}}$ & $\overline{\bar{z}}$ & $\overline{\bar{z}}$ & $\overline{\bar{z}}$ & 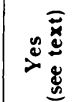 & 离 \\
\hline$\stackrel{2}{2}$ & z & z & ฉ̊ & z̊ & $\stackrel{\searrow}{\check{\nu}}$ & z̊ & $\sqrt{z}$ & $\stackrel{2}{z}$ & 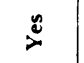 & z̊ & $\stackrel{2}{ }$ & $\grave{z}$ & $\underset{\nu}{\mathscr{X}}$ & $\stackrel{\bar{x}}{\bar{x}}$ & $\stackrel{2}{z}$ & $\stackrel{\check{\nu}}{\check{\nu}}$ \\
\hline$\frac{5}{\pi}$ & $\frac{5}{\pi}$ & $\frac{5}{\pi}$ & $\frac{5}{\pi}$ & $\frac{a}{\pi}$ & $\frac{5}{\sigma \pi}$ & 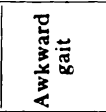 & 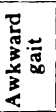 & 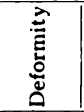 & $\frac{\frac{5}{\pi}}{\tilde{\pi}}$ & 产 & 点 & $\frac{5}{\pi}$ & $\frac{5}{\pi}$ & $\frac{a}{\pi}$ & 点 & $\frac{5}{\bar{E}}$ \\
\hline 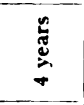 & 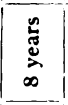 & $\stackrel{0}{2}$ & 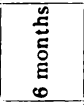 & 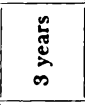 & 总 & 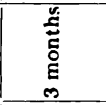 & 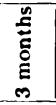 & 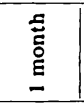 & 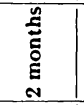 & 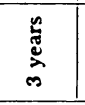 & 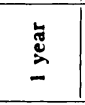 & 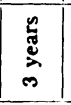 & 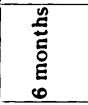 & 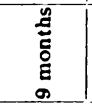 & $\begin{array}{l}\underline{\tilde{B}} \\
\text { 兽 } \\
\end{array}$ & $\stackrel{\breve{d}}{\check{\Xi}}$ \\
\hline $\begin{array}{l}\bar{\delta} \\
\text { : } \\
\text { : }\end{array}$ & 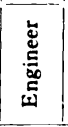 & 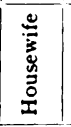 & $\begin{array}{l}\overline{8} \\
\text { : } \\
\text { U. }\end{array}$ & 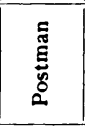 & 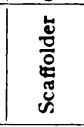 & $\begin{array}{l}\overline{8} \\
\text { 离 }\end{array}$ & 1 & $\bar{z}$ & 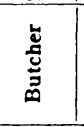 & $\begin{array}{l}\overline{8} \\
\text { s. } \\
\text { w }\end{array}$ & $\begin{array}{l}\overline{8} \\
\overline{8} \\
\bar{n}\end{array}$ & 总 & $\begin{array}{l}\overline{8} \\
\overline{4} \\
\vdots\end{array}$ & I & 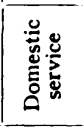 & 氖 \\
\hline 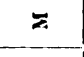 & $1=$ & 14 & $\approx$ & $z$ & $=$ & L & $\therefore$ & 12 & $\Sigma$ & $\Sigma$ & 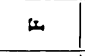 & 12 & is & L & 12 & $=$ \\
\hline$\subseteq$ & $\stackrel{\sim}{\circ}$ & 用 & \pm & $\underline{\infty}$ & $\underline{\varphi}$ & $\underline{m}$ & $\underline{m}$ & $\underline{\underline{O}}$ & $\underline{\underline{O}}$ & \pm & $=$ & $\approx$ & $\varrho$ & $\varrho$ & \pm & $\dddot{m}$ \\
\hline$\Xi$ & 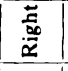 & 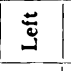 & $\stackrel{\Xi}{\Xi}$ & 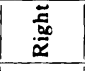 & $\Xi$ & 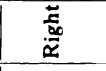 & $\Xi$ & 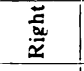 & 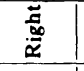 & $\begin{array}{l}\overrightarrow{\tilde{E}} \\
\ddot{\alpha}\end{array}$ & 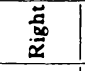 & 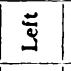 & 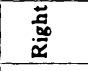 & $\Phi$ & 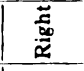 & 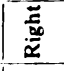 \\
\hline \pm & 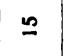 & $\mathscr{0}$ & $=$ & 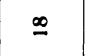 & - & ๙ & $\bar{N}$ & สี & $\stackrel{\Re}{\pi}$ & $\vec{\sim}$ & జ & $\stackrel{2}{*}$ & ๙ิ & \$ & ริ & ஜ \\
\hline
\end{tabular}

vol. 37 B, NO. 2, MAY 1955 


\section{OBSERVATIONS AND DISGUSSION}

Table I gives a general account of the patients and of the clinical and radiological findings.

Peroneal spastic flat foot is rare. Harris and Beath (1947) found seventy-four cases among 3,619 Canadian army recruits, an incidence of 2 per cent. The condition is seldom found in patients over the age of twenty. In my series there were six patients over twenty; in these, symptoms dated from a period of unusually severe exertion. In general, the patients are in late adolescence or have recently acquired a more strenuous occupation. The records of the height, weight and build show that stature plays no particular part. As to general intelligence, excluding one Mongol there were eight patients with mental backwardness, an incidence higher than would be expected in a group of this size. The commonest initial symptom was pain, and it was unusual to obtain a history of recent injury. The foot generally assumed a valgus position, but the arch itself was seldom altered. There were signs of neurological disease in one case, whereas Haberler and Winkler (1934) found pyramidal signs in ten out of forty-two cases. When any suspicion of hysterical manifestations was aroused the help of a psychiatrist was sought, and in one case this diagnosis was confirmed, the patient later developing a hysterical inversion deformity.

Radiographic findings-The incidence of developmental tarsal anomalies in the general population is unknown. Harris and Beath (1947) found a calcaneo-navicular bar in one of 3,619 army recruits but they did not assess the frequency of talo-navicular bridge. Pfitzner (1896) examined 840 foot skeletons and found a calcaneum secondarium in 1 per cent. The fifty feet from normal adolescents radiographed as a control series in this investigation showed no bony abnormality.

In the present series of thirty abnormal feet, nine showed a calcaneo-navicular anomaly varying in degree from a prolongation of the anterior process of the calcaneum to a complete

bony bar. Four showed the talo-calcaneal bridge described by Harris and Beath (1948). Two of these four showed mid-tarsal lipping, said to confirm the presence of this developmental anomaly.

Other radiographic abnormalities included: An abnormally high ridge of bone on the superior surface of the navicular adjacent to its articulation with the talus (one case); an abnormal joint between two bony prominences below the lateral malleolus (one case) (Fig. 5); accessory navicular bone (two cases); vertical talus (two cases); marked osteoporosis (two cases). The presence of a talo-calcaneal bridge was presumed but could not be definitely established in one other case.

The remaining eight feet showed no radiological abnormality. Tracings of the relevant part of the tarsal radiographs are shown in Figure 1.

The inter-relation of physical signs and tarsal anomalies-It is upon this aspect of the problem that there has been a wide variance of opinion. Harris and Beath (1948) wrote: "We shall show that most cases of peroneal spastic flat foot are due to tarsal anomalies." This statement was based upon the study of seventeen cases. In twelve there was a talocalcaneal bridge, and in three a calcaneo-navicular bar; the remaining two patients had tarsal rheumatoid arthritis. These authors suggested that in cases due to tarsal anomalies the feet have always been flat, and that the history dates back to early childhood.

On the other hand Seddon (1932) wrote: "The interference with the action at this [midtarsal] joint resulting from the presence of the calcaneo-scaphoid bar explains the clinical picture." He gave an explanation for the fact that although the anomalies are developmental, the symptoms only appear in late childhood. He suggested that in childhood the interference in smooth action of the midtarsal joints is compensated for by their cartilaginous covering, but at twelve to fourteen this cartilaginous covering is lost, and with it the compensation. This view accords with other authorities in suggesting that the presence of a bony anomaly is sufficient to account for the symptoms and signs, the inference being that the anomaly is an incorrigible bar to inversion. 


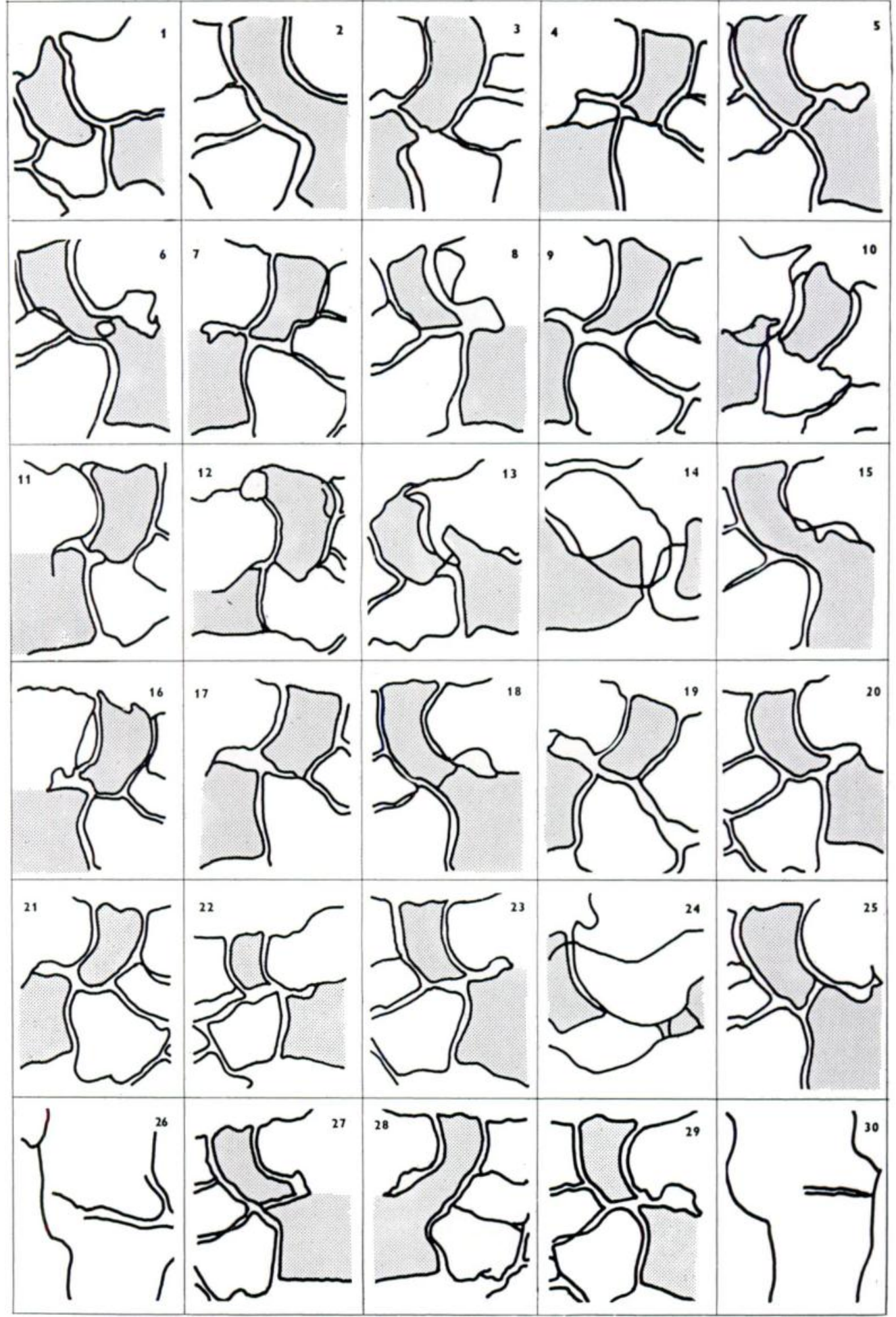

Fig. 1

Tracings from radiographs showing the relevant parts of the tarsus of each case. The navicular and the calcaneum are shown stippled for clarity. In cases $4,7,9,11,19,21,22$ and 29 there was no radiological anomaly. 
All the feet of the present series were manipulated under anaesthesia, sometimes with the use of a relaxant. This has produced one of three results: 1) The foot has fallen without effort into the neutral position, from which it could easily be placed into full inversion (sixteen cases) ; 2) the foot has assumed a position of less inversion, and full inversion has been obtained only with force, accompanied by the tearing of adhesions (seven cases); 3) the foot has remained in a position varying between neutral and the pre-anaesthetic state (seven cases).

Of the sixteen feet in which full inversion was easily obtained, four had the type of calcaneo-navicular anomaly usually considered to indicate permanent incorrigible rigidity. Two others had radiographic changes which, if manipulation had not been tried, would have been thought sufficient to account for the clinical condition. The remaining ten included the eight with normal tarsal architecture and two with minor findings of doubtful significance.

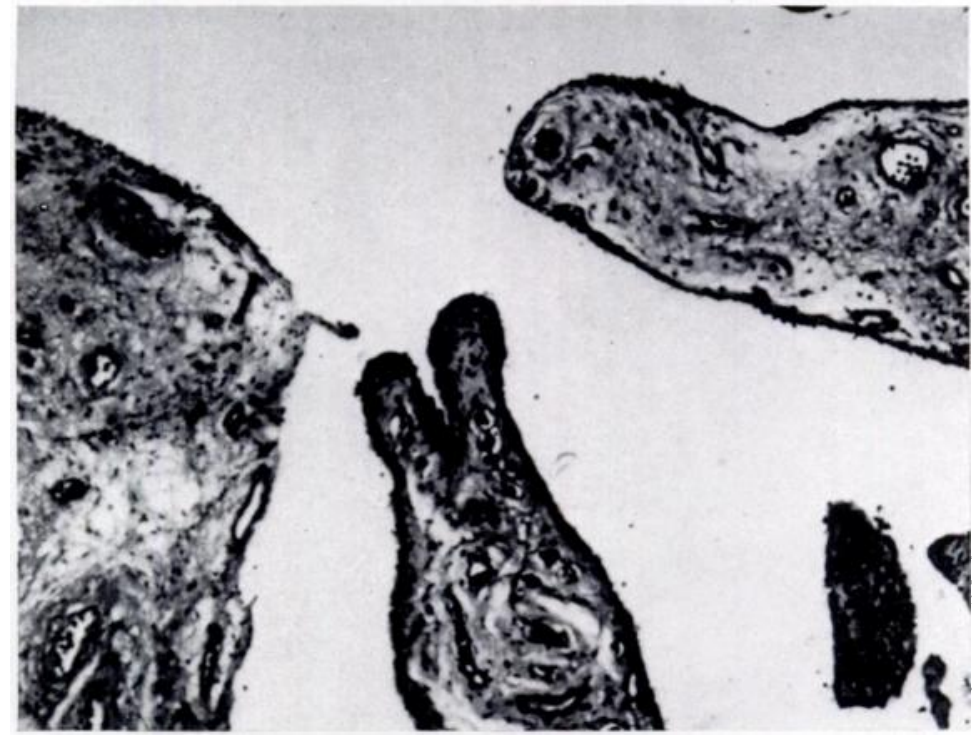

FIG. 2

Photomicrograph $(\times 75)$ of the synovial membrane of the posterior talo-calcaneal articulation of Case 10 . The villi show mucoid change. There is no evidence of inflammation.

Of the seven feet in which full inversion could be reached after the tearing of adhesions, three possessed tarsal anomalies that would have suggested complete rigidity. The seven feet showing absolute rigidity showed radiographic changes of varying type and degree.

Thus there was no constant relationship between the degree of rigidity and the degree of radiographic abnormality, a finding opposed to that of Seddon (1932), Webster and Roberts (1951), and others. This series shows that the clinical picture of peroneal spastic flat foot can be seen in feet with or without tarsal anomalies. Rigidity of the foot under anaesthesia indicates a severe developmental anomaly, but mobility does not necessarily imply a normal tarsal skeleton.

The irritable focus hypothesis-Lapidus (1946) studied published opinions on the origin of the reflex chain leading to spasm. He described dissections in which the interosseous talo-calcaneal ligament was found to be slack in eversion, and suggested that this anatomical finding " provides a logical explanation for the exclusive tendency of the pronators to become spastic." He suggested that the causative lesion was either traumatic or inflammatory. No writer has found any convincing evidence of a true inflammatory lesion in or near the interosseous ligament, and at present it seems unwise to incriminate the ligament solely on 
account of its convenient anatomical properties. During the course of subtalar and midtarsal fusions which became necessary in four of my cases, no evidence of an inflammatory or traumatic lesion was found. Figure 2 shows the histology of the synovial membrane of the posterior subtalar joint in one case, and apart from some mucoid degeneration, presumably due to lack of use, no abnormality is seen.

Abolition of the spasm after the injection of local anaesthetic into the sinus tarsi would suggest that the afferent impulses arose there, but, although $I$ have attempted this in six cases, I have not succeeded in producing any result, nor have I witnessed any benefit from the attempts of others.

The reflex spasm hypothesis - Harris and Beath (1948) were the first to throw doubt on the concept of reflex muscle spasm as the cause of the deformity. They suggested that the "peronei " had undergone adaptive shortening. My studies with these feet under anaesthesia have not confirmed this supposition, and I was able to get full inversion without force in sixteen of the thirty feet. Our knowledge of reflex muscle spasm is incomplete, but the electromyograph can be used to indicate whether the increased tension in a muscle is due to organic contracture or to stimulation from its motor nerve. In the former the recording will show silence at rest, whereas in the latter it will show sustained motor unit activity. I made recordings, using surface electrodes and needle electrodes, from the peroneal muscles in two of my cases. In both full inversion under anaesthesia had been obtained, so organic shortening could not be incriminated, and the recordings obtained showed no increase in motor unit activity-a totally different picture from that produced by muscle spasm seen elsewhere. In both these cases the outer compartment of the leg was opened in order to be certain that the needle was in the intended spot. Although there was an increase of tension of the peroneus brevis in these cases, the electromyograph showed no motor unit activity. If this holds good for all cases, we are dealing with a condition in which a muscle-tendon unit can show an increase of tension without either organic shortening or a volley of contractile impulses arriving along its motor nerve. It may be that this increase in tone in a muscle belongs to the class of phenomena (attributed to passive elastic tension) mentioned by Clemmesen (19:5l) in which the tone is produced by changes in local muscle chemistry quite independent of its nerve supply.

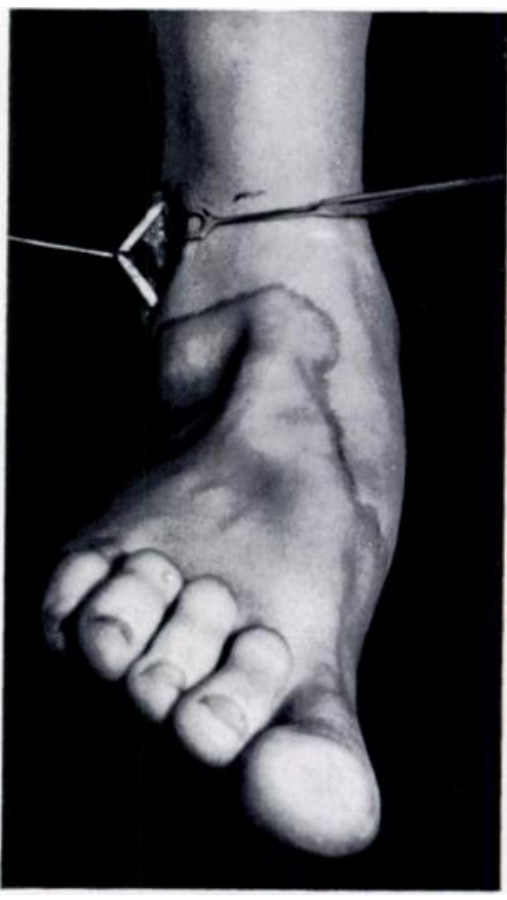

Fig. 3

Case 24-Fxposure of the peroneal tendons under local anaesthesia. The deformity is well marked. The hook is round the tendon of peroneus longus. It is not unduly tight. Peroneus brevis beneath this was in a state of increased tension, and could not be withdrawn through the wound.

On the other hand, the needle electrode electromyograph in my hands is capricious, and the failure in my two cases to find any electromyographic evidence of reflex spasm may be due solely to technical difficulties; so on this slender evidence it would be unwise to swing away from the muscle spasm explanation favoured by other writers in this field.

Associated findings-Several other observations have been made in the course of the further investigations mentioned earlier.

The muscles responsible-Previous workers have stated that although other muscles play a part in the production of the deformity, the peronei are the main deforming agents. There has been a wide assumption that, since the peroneus longus and peroneus brevis lie in the

VOL. $37 \mathrm{~B}$, No. 2 , MAY 1955 
same anatomical compartment of the leg, their function as evertors at the midtarsal and subtalar joints is a like one. From dissections of the foot and from observations on other foot conditions it has been noted that the peroneus brevis is the stronger cvertor and that the peroneus longus pronates the forefoot, flexing the first metatarsal segment, and only sacondarily producing eversion of the whole foot. In many cases of peroneal spastic flat foot all muscles capable of exerting an evertor action are seen to be in a state of increased tension. In some cases, however, it has been my impression that clinically the peroneus brevis has been producing the deformity, the peroneus longus being normal; and the view that the "peronei" are responsible is false. I have explored the muscles in three cases under local anaesthesia to examine the tone in the two peronei. In these cases the peroneus longus was not unduly taut, but the peroneus brevis tendon was very tight. For instance, it was possible to withdraw the longus tendon on an aneurysm needle (Fig. 3), which was not possible with the brevis. This point has been investigated in only three cases, but, taken with the fact

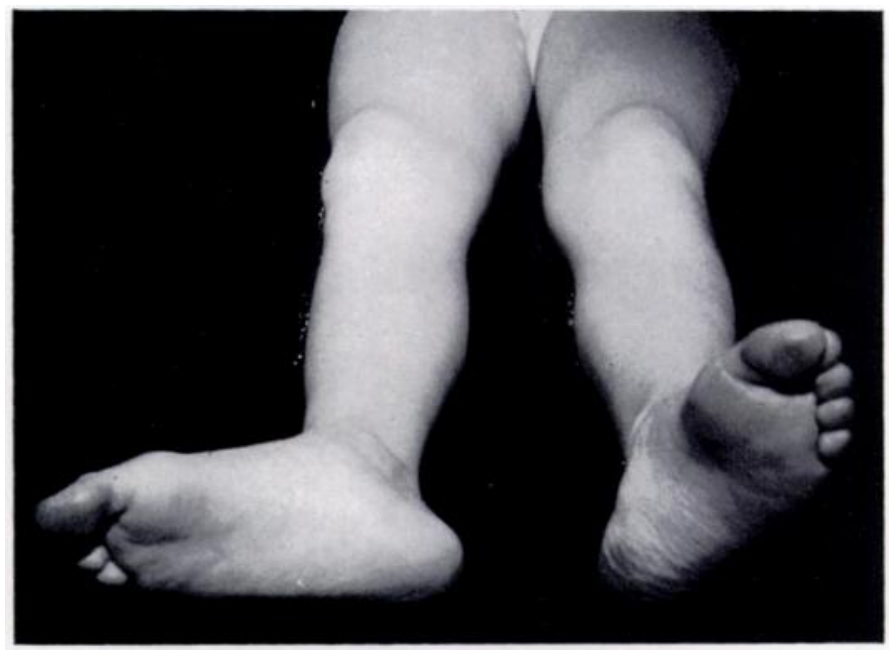

Fig. 4

Case 18. Marked lateral rotation at the hip. Right peroneal spastic flat foot of eighteen months' duration. The patient is under anaesthesia.

that the nature of the deformity does not seem to be one characteristic of peroneus longus overaction, it suggests that in many cases it is the brevis that is contributing mostly to the deformity.

Lateral rotation of the whole limb-It was noticed in six cases that if an anaesthetic was given with a relaxant, and the two big toes were held together and then released, the normal leg would roll out and finally assume a position of about 30 degrees' lateral rotation at the hip. The leg having the peroneal spastic flat foot would fall immediately into 90 degrees' lateral rotation. This limb showed a limitation of movement by soft-tissue contracture at the hip joint. The presence of this phenomenon under relaxant drugs precludes the possibility of its being due to lateral rotator spasm, and it is suggested that as the gait of these patients is one of habitual lateral rotation at the hip, there is adaptive shortening of the soft tissues in this region (Fig. 4).

Accessory tarsal articulation-A separate articulation between the inferior aspect of the lateral malleolus and a facet on the lateral aspect of the calcaneum was seen in one case (Fig. 5) and the joint was explored. It contained a synovial cavity which did not communicate with the synovial cavity of the ankle or subtalar joint. Forced inversion opened this joint.

Exploration of the sinus tarsi and its environs in another case disclosed that, although 
there was an extensive calcaneo-navicular anomaly and the hindfoot was rigid even under anaesthesia, this anomaly was not the sole factor limiting inversion. Two strong ligaments were seen passing from the supero-lateral aspect of the calcaneum to the lateral side of the neck of the talus (Fig. 6). Between them was an unimportant synovial fringe. The stouter

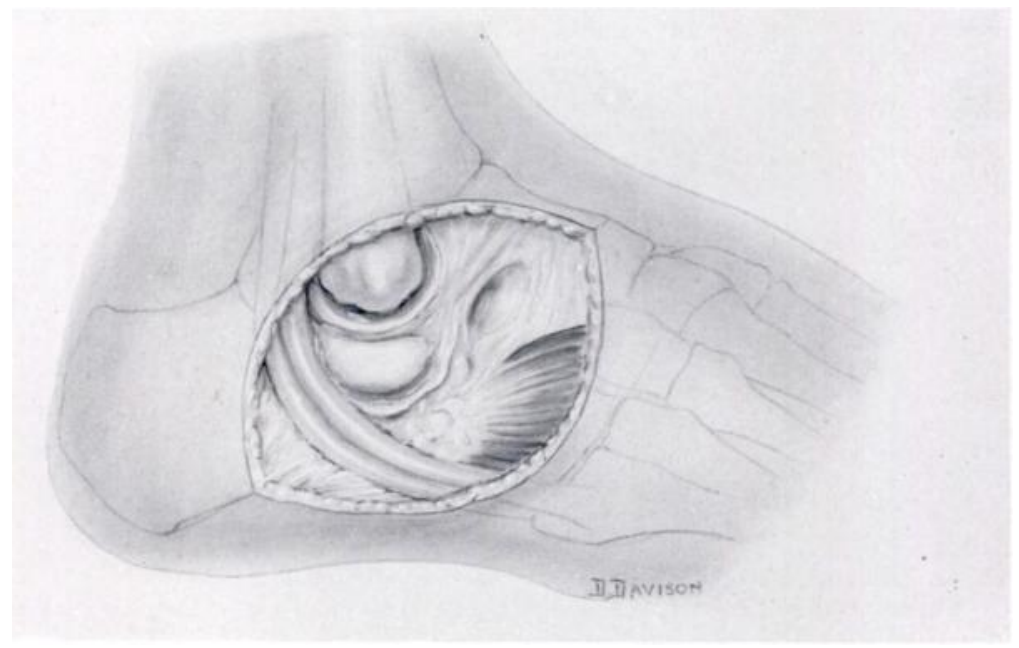

Fig. 5

Case 1 Accessory articulation between the lateral malleolus and a tuberosity on the lateral aspect of the calcaneum. The accessory joint has been opened by inversion.

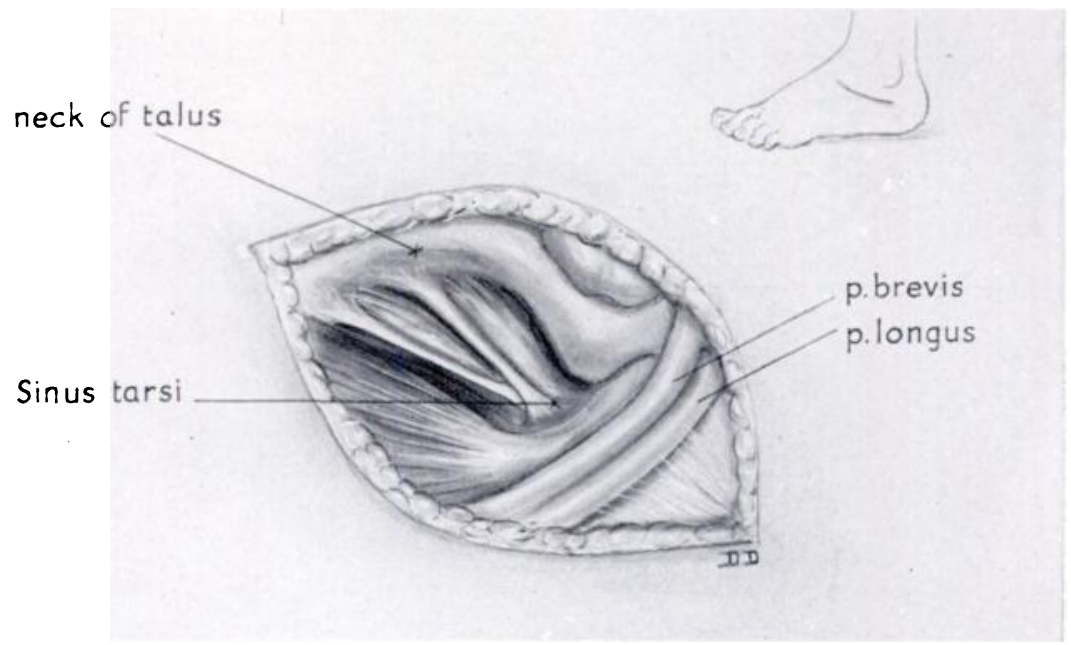

Fig. 6

Case 6 - The sinus tarsi and related structures. The stem of the inferior extensor retinaculum or "ligamentum frondiforme" of French anatomists has been omitted for clarity. Yote that the ligamentum cervicis (Wood Jones 1949) is represented as two ligaments of some strength.

ligament arose from the anterior aspect of the posterior articular facet on the calcaneum, and was a dense thickening of the anterior capsular ligament of the joint. (The normal foot has one strong ligament only in this situation, the ligamentum cervicis, described by Wood Jones in 1949). Its division allowed almost full inversion, the structures limiting full inversion then being the skin and soft tissues.

Vol. $37 \mathrm{~B}$, No. 2, MAY 1955 


\section{RESULTS OF TREATMENT}

The results are shown in Table I. It will be seen that sixteen of the thirty feet had a full range of tarsal movement under anaesthesia, and of these four had severe tarsal anomalies. It is these rare cases which show good inversion under anaesthesia, in spite of tarsal anomalies, that are the most puzzling of the whole series.

Of the sixteen feet in which a full range of inversion could be produced under anaesthesia without any force, twelve showed powerful active inversion after the removal of the plaster at three months. The other four had reduced their degree of inversion while in a padded walking plaster, and after it was removed they could invert just beyond the neutral, but could not reach full inversion. Of these four, one had a vertical talus, one had an accessory tarsal navicular, one showed marked porosis, and the fourth showed no radiographic abnormality.

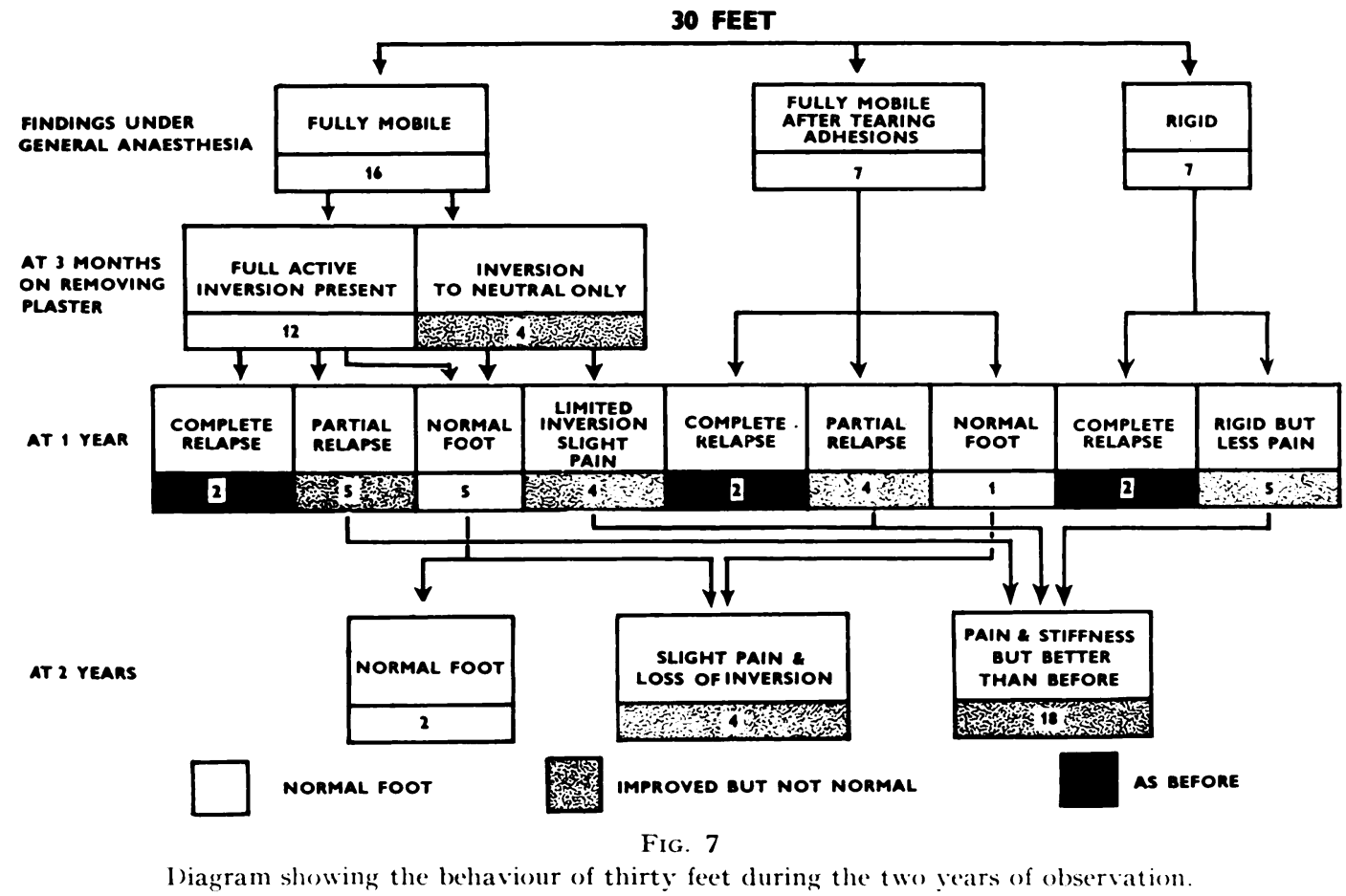

Results one year after beginning of treatment-The results at one year showed that of these sixteen feet six were still symptom-free and possessed a full range of active inversion. The four mentioned above in which full passive inversion was present after removal of the plaster, but limited active inversion, remained the same at one year. They had inversion just beyond neutral, but the natural lie of the foot was everted, and there was a return of slight pain. The remaining six relapsed to some degree; two completely, and four having evertor spasm, loss of inversion, and slight pain, although considerably less than when they first attended.

To summarise this: of sixteen feet freely mobile under general anaesthetic, six were normal; eight were slightly better than before manipulation, although they had some pain and some valgus; and two had reverted to the fully established painful deformity. Of the two with complete relapse, one had a calcaneo-navicular synchondrosis and the other a complete bar.

Of the seven feet in which full inversion was obtained only after tearing adhesions, one was normal a year later, four lacked full inversion but caused no pain, and in two pain and 
valgus had returned as before. Thus five out of seven were still better than they were before treatment. Of these five, one had no bony anomaly, three had minor anomalies, and one had a complete bar. The two feet that had relapsed completely both had calcaneo-navicular synchondroses.

Taking these together as one group in which full inversion was possible under anaesthesia, we find at one year that of twenty-three feet seven were normal, and a total of nineteen were improved on their condition before manipulation.

Of the seven feet that remained fixed in eversion after the manipulation, two were slightly better at one year, and five were unchanged by the manipulation. Of these seven, four had talo-calcaneal bars, one had a tongue-like prolongation of the front of the calcaneum, and two had severe midtarsal lipping. Two of the seven received subtalar and midtarsal fusion at two years.

Results two years after beginning of treatment-Of the twenty-three feet in which full inversion was possible under anaesthesia, we have seen that seven were normal feet at one year. Three of these remained normal at two years. Of the remaining four patients one developed a hysterical inversion deformity and the other three lost some of their inversion range and complained of slight pain after exertion. The seventeen feet that were improved but not normal at one year deteriorated during the second year, and eight returned more or less to the same state as when first seen. Four feet required subtalar and midtarsal arthrodesis. Of the original total of thirty feet, two were normal, sixteen were improved in varying degree, eight were the same, and four required operation. An analysis of these results is shown in diagrammatic form in Figure 7.

Comment-The feet that were improved by the treatment belong to the group which showed mobility under anaesthesia, and cures were seen only in those feet with normal tarsal architecture.

Crushing of the nerves to peroneus brevis gave temporary relief of signs and symptoms, but often the evertor spasm occurred in other muscles, and with it a return of symptoms.

Observation of these cases for two years did not reveal the evolution of rheumatoid arthritis in any one. Three patients had a sedimentation rate of over 15 millimetres in one hour when first seen; one of these, and one other, showed radiographic osteoporosis, but none developed any further changes indicating a generalised disturbance.

\section{SUMMARY AND CONCLUSIONS}

1. This paper reports the investigation and the results of a line of treatment in thirty feet showing the peroneal spastic flat foot deformity. The questions that have aroused controversy are discussed, the evidence for previous opinions is examined, and some phenomena in relation to this condition are described.

2. It is suggested that previous opinions on this condition have been misleading, and have in many cases been made after incomplete investigation of too few cases.

3. Peroneal spastic flat foot can occur without a developmental tarsal anomaly.

4. The presence of a tarsal anomaly does not necessarily mean that the foot is incorrigibly stiff, and some of these feet show a full range of movement under anaesthesia.

5. There is no evidence from this series of cases to suggest that organic nervous disease or psychiatric disturbances played a significant part in the production of the deformity.

6. There is no evidence to suggest that the deformity is a manifestation of generalised rheumatoid arthritis.

7. This investigation does not reveal the cause of the deformity when the tarsal skeleton is normal, nor does it help to explain the reason for the onset of symptoms in a developmentally abnormal foot.

8. It is suggested that a tarsal anomaly makes the foot more likely, under average stress, to break down in this way, and that this deformity is also assumed by architecturally normal

vOL. $37 \mathrm{~B}$, NO. 2 , MAY 1955 
feet under heavy stress. In view of the frequency of minor tarsal anomalies among this series of thirty feet, it seems likely that all feet presenting the deformity of peroneal spastic flatness are to some degree structurally abnormal, although the exact site of the abnormality may escape us.

My thanks are due to Mr D. Ll. Griffiths for help with this paper; to Sir Harry Platt and Mr John Charnley for permission to study their cases; and to the Department of Medical Illustration, Manchester Royal Infirmary, for their photographic work.

\section{REFERENCES}

Clemmesen, S. (1951): Some Studies on Muscle Tone. Proceedings of the Royal Society of Medicine (Section of Physical Medicine), 44, 637.

Haberler, G., and Winkler, W. (1934): Neue Gesichtspunkte zur Pathogenese des muskulär fixierten Plattfusses. Zeitschrift für orthopädische Chirurgie, 61, 471.

HARRIS, R. I. (1954): Personal communication.

Harris, R. I., and Beath, T. (1947): Army Foot Survey. Ottawa: National Research Council of Canada,44. Harris, R. I., and Beath, T. (1948): Etiology of Peroneal Spastic Flat Foot. Journal of Bone and Joint Surgery, 30-B, 624.

Jones, F. Wood (1949): Structure and Function as Seen in the Foot. Second edition, 118. London: Baillière, Tindall and Cox.

Jones, R. (1897): Peroneal Spasm and its Treatment. Report of Meeting of Liverpool Medical Institution held 22nd April 1897. Liverpool Medico-Chirurgical Journal, 17, 442.

Jones, R. (1916): The Soldier's Foot and the Treatment of Common Deformities of the Foot. British Medical Journal, 1, 709.

Lapidus, P. W. (1946) : Spastic Flat-Foot. Journal of Bone and Joint Surgery, 28, 126.

Pfitzner, W. (1896) : Die Variotionen im Aufbau des Fussskeletts. Morphologische Arbeiten, 6, 245.

Seddon, H. J. (1932): Calcaneo-Scaphoid Coalition. Proceedings of the Royal Society of Medicine (Section of Orthopaedics), 26, 419.

Webster, F. S., and Roberts, W. M. (1951): Tarsal Anomalies and Peroneal Spastic Flatfoot. Journal of the American Medical Association, 146, 1,099. 